Vol. 07, No. 03, pp. 106-119, September 2014

\title{
CHARACTERISTICS AND PROPERTIES OF EPOXY/POLYSULFIDE COMPOSITE MATERIALS REINFORCED BY CARBON NANOTUBES
}

\author{
Adnan Nemaa ${ }^{1}$, Ibtihal Abed Al-Razaq ${ }^{2}$, Ekhlas Edan Kader ${ }^{3}$ \\ ${ }^{1}$ Professor, Technical College / Baghdad. \\ ${ }^{2}$ Assistant Professor, University of Technology. \\ ${ }^{3} \mathrm{PhD}$ student, University of Technology \\ E-mail: eng-ekhlas@yahoo.com \\ (Received: 23/6/2013; Accepted:12 /1/2014)
}

\begin{abstract}
In this research, multi-walled carbon nanotubes (MWCNTs) were used to enforce the blend of epoxy /polysulfide and then tensile and wear behavior of this reinforcement were evaluated. For achieving this goal, different weight percentages of MWCNT (0.2-0.6 wt \%) were dispersed in the epoxy resin then polysulfide resin is added and mixed with two curing agents. Experimental results have shown significant difference between epoxy/polysulfide and CNT /epoxy /polysulfide in mechanical properties. With 0.20.6\% MWCNTs we observed an increase in Young's modulus from 245 to273 MPa, tensile strength from 30.5 to $38.9 \mathrm{MPa}$ and fracture strain from $12.4 \%$ to $14.2 \%$. For understanding the structure and morphology of nanocomposite, the dispersion states were studied using scanning electron microscopy (SEM) and field emission electron microscopy (FESEM).
\end{abstract}

Keyword: Composite Materials, Carbon Nanotubes, Mechanical Properties, Polysulfide.

\section{1- INTRODUCTION}

Polysulfide resins are the first synthetic elastomers which were manufactured on a commercial scale in United State. Liquid polysulfide resins are obtained by splitting preformed high molecular and cross-linked latex into shorter di and tri-functional chains.SHterminated polysulfide is mainly used as base polymers in elastic sealants for insulating-glass windows and in construction purposes.

The liquid polysulfide is converted to elastomers by chain extension and cross linking. During the curing process the terminal thiol groups react with each other to form disulfide bonds. Polysulfide-based materials are known for their special strength and relaxation properties. Cured polysulfide shows low gas and vapor- diffusion rates, a high chemical resistance especially against fuel and solvents and good weathering stability. 
Because of their highly reactive SH-end groups liquid polysulfide can be used as starting materials for other poly-functional macromolecules ${ }^{(1)}$. Epoxy/polysulfide is a polymer combine the unique properties of polysulfide (softness) with those of epoxies(hardness), it uses in different objects such as producing paint, gum and elastic sealant, flexible anti-corrosion coatings, relieving cracks of broken concretes in building, sewage pipes and surface of streets, producing marine color and two-walled glass ${ }^{(2)}$.

To further strengthen the properties of current polymer materials, the addition of many kinds of inorganic fillers has already been researched and applied extensively. The size and dispersion characteristics of inorganic particles have a great effect on the comprehensive properties of polymer composites. The application of nanometer fillers to polymer materials is a promising channel for property modification.

Some nano-fillers have improved polymer performance remarkably because of their high specific surface area compared to conventional fibers or particles ${ }^{(3)}$. Since discovery of multi-walled carbon nanotube (MWCNT) in 1991 by Iijima, and synthesis of single-walled carbon nanotube (SWCNT) in 1993 by him and his coworkers ${ }^{(4)}$, CNTs have become one of the most promising fillers for reinforcement and multi-functionality because of their exceptional mechanical (elastic modulus in the range of 500-600 GPa and tensile strength close to $200 \mathrm{GPa})^{(5,6)}$ electrical, and thermal properties ${ }^{(7,8)}$.Many studies have shown significant property enhancement in CNT-filled epoxies ${ }^{(5,9)}$. For example, a $20 \%$ increase in storage modulus at room temperature was achieved in a bisphenol-F type epoxy with only 0.3 wt $\%$ of single-walled carbon nanotube $(\mathrm{SWNT})^{\left({ }^{(9)}\right.}$.

There are a few publications about polysulfide polymer nanocomposite. Guchhait et al. have been modified epoxy resin with polysulfide polymer and then prepared nanocomposites by dispersing the nanosilica in polymeric matrix. The effect of nanosilica on morphology, mechanical, thermo-mechanical and dielectric properties of epoxy/polysulfide has been studied by them ${ }^{(10)}$. In the similar research Zhang and Shi JH have studied morphology, mechanical and thermal properties of polyurethane/polysulfide reinforced with 1,3 , and $5 \mathrm{wt} \%$ nanoclays ${ }^{(11-13)}$. In this study we considered the effect of addition of MWCNT on properties of epoxy/polysulfide blend. Despite significant need, this topic has not yet been addressed sufficiently and there remain controversies in this area. As polysulfide epoxy is used in industrial and special coatings, mechanical properties are very important in resin which must be investigated. For this mean, three different samples including $0.2 \%$, $0.4 \%$ and $0.6 \%$ by weight of MWCNT were prepared and a comparison on the properties of these nanocomposites provided preliminary results. Also, tensile, wear resistance of each nanocomposite were determined. 


\section{EXPERIMENTAL DETAILS}

\subsection{Material}

MWCNTs with minimum purity of 95\%, 3-15 number of walls, outer diameter of 2-6 $\mathrm{nm}$, inner diameter of 2-6 $\mathrm{nm}$, length of1-10 $\mu \mathrm{m}$ and density of $0.15-0.35 \mathrm{~g} / \mathrm{cm}^{3}$ were obtained from Plasma Chem GmbH; epoxy resin type (Quickmast $105^{\circledR}$ (DCP)), containing epoxide group, which is thermoset resin and manufactured by commercially produce from Quick Mast company .The hardener from the same company are used to achieve curing of the epoxy resin and epoxy properties are shown in table (1). Considering polysulfide resin, one of the most properties that distinguishes this rubber is that it contains sulfur as part of a series of linear polymer whose trademark is (DCP). The polysulfide is supplied in the shape of white dough that changes to elasticity shape by adding $\mathrm{PbO} 2$ (black dough) in the ratio 1:16 with density (1.35) $\mathrm{gm} / \mathrm{cm}^{3}$ as table (2) contains properties of polysulfide polymers.

\subsection{Preparation of MWCNT/epoxy polysulfide composite}

Three series of composite were prepared with different content of MWCNTs as 0.2, 0.4 and $0.6 \mathrm{wt} \%$. First MWCNTs were mixed in epoxy resin via ultrasonic (Hielscher UP 400S) for $30 \mathrm{~min}$ and then polysulfide resin was added and mixing was continued for $1 \mathrm{~h}$ by (WiseTis) homogenizer with speed of $15000 \mathrm{rpm}$ with ten minute work and ten minute off to keep the device temperature low. Then samples were placed in vacuum for $30 \mathrm{~min}$ at $80^{\circ} \mathrm{C}$ to remove bubbles and after this stage, aliphatic amine hardener and polysulfide hardener were added to composite while were mixed with low speed. After uniform mixing, the mixture was poured into the prepared mould and left for complete curing to be done.

\subsection{Characterization of MWCNT/epoxy polysulfide composite}

Fourier transform infrared (FTIR) spectroscopic measurements were done using a FTIR spectrometer (Perkin Elmer; model of SpectraI). The FTIR spectra of pristine MWCNTs were obtained in a transmittance mode by mixing a small amount of the nano tubes in $\mathrm{KBr}$ pellets. Raman spectroscopy (Thermo Nicolet Dispersive Raman Spectrometer) was used to investigate the structural changes of MWCNTs .Second harmonic@532 nm of a Nd:YLF laser was used as the light source. Furthermore, morphological characterization of the composites was carried out using scanning electron microscopy (Zeiss; model of LEO 1455VP). For SEM observation, samples were coated with platinum via sputtering for $30 \mathrm{~s}$. FESEM images of nanocomposites were recorded on a field emission scanning electron microscope (Hitachi S-4160) operating at $15 \mathrm{kV}$ to determine particle size of MWCNTs in matrix. 


\subsection{FTIR spectroscopy}

FTIR spectra of the samples are shown in Fig.(1) No obvious vibration of carboxylic groups appears for pristine MWCNTs around $1700 \mathrm{~cm}^{-1}$, but, vibrational modes of 3475 are attributed to the $\mathrm{O}-\mathrm{H}$ stretching, carboxyl stretching and $\mathrm{C}-\mathrm{O}$ bending, respectively, as reported previously. The presence of the characteristic peak at $3425 \mathrm{~cm}^{-1}$ is attributed to remained moisture in MWCNTs which usually is appears in FTIR; but increase in intensity of this peak is an indication that the above chemical treatment led to the graft of polar functional groups such as $(-\mathrm{OH})$ on the surface of MWCNT ${ }^{(14,15)}$.

\subsection{Raman spectroscopy}

Raman spectroscopy is a useful method for investigation of the low energy elementary excitations in carbon nanotubes like to characterize their structural, electronic, vibrational and magnetic properties $\left({ }^{16,17)}\right.$. The main features of CNTs in the Raman spectrum (Fig. 2) are the radial mode band (100-400 $\mathrm{cm}^{-1}$ ), irregular induced D-band which appears at around $1350 \mathrm{~cm}^{-1}$, G-band which represent the crystalline graphitic and tangent vibrations of sp2 carbon (1500-1600 $\mathrm{cm}^{-1}$ ), and D_-band which represents the overtone of the disorder $\left(\_2600 \mathrm{~cm}^{-1}\right)$. Osswald et al. ${ }^{[18,19]}$ reported that in MWCNTs the D-band appears due to defects in the tube walls. The value of the intensity ratio of the D and G-bands ID/IG represents the degree of disorder on the MWCNTs structure. Also, intensity ratio of the D and-bands can determine the degree of disorder on the MWCNTs. A growth in D/G or reduction in ID/IG indicates higher defect concentration or a higher degree of disorder. Observing the functionalized MWCNTs, the G-band is less affected by defects from functionalization as compared to the D-band.

In the current study, the radial breathing mode (RBM) in the Raman spectra which is a direct measurement of the core nanotube diameter ${ }^{(20)}$ was not evident. Since MWCNTs used in the current study contained a minimum average of about 3-15 shells, in height the Raman spectra of these MWCNTs would correspond to a radial mode band with very low frequency and weak intensity.

\subsection{SEM and FESEM}

SEM images from fracture surfaces were used to observe the morphology of the neat resin and nanocomposites in detail. As it has been shown in Fig. (3), the morphology of the all MWCNT-nanocomposite samples is considerably changed in comparison with the respective neat epoxy polysulfide resin (Fig. 3a and b). The smooth fracture surfaces of the neat epoxy polysulfide matrices became rough after the attendance of the nanotubes due to agglomeration of CNTs. These results are in good agreement with previous reports ${ }^{(21,22)}$. In this work, both pure nanotubes seem to be well impregnated by the epoxy polysulfide 

matrices and aggregates are under $100 \mathrm{~nm}$. No micrometric aggregates are observable in the images from surface and fracture surface of nanocomposites. However, the pure MWCNT aggregates are concentrated in small areas, as shown in the composite surface.

\section{3-TENSILE TEST}

Tensile testing was carried out on samples by ASTM D-638 using a testing machine (SANTAM; STM - 5). The measurements were carried out at $25 \pm 1 \mathrm{C}$ using an extension rate of $1 \mathrm{~mm} / \mathrm{min}$. The tensile stress-strain curve is a tool to provide data on toughness, ultimate tensile strength, ultimate elongation at break and Young's modulus.

Tensile test was done to evaluate the effect of MWCNT on the mechanical properties of composite samples. The results of ultimate tensile properties are presented in Fig. (4) and Fig. (5). as indicated in this Figs., the addition of MWCNT led to an increase in both Young's modulus and the ultimate tensile strength values. due to increasing in value of $0.4 \%$ MWCNTs and then reduced at $0.6 \%$ MWCNT . This result may be explained by the fact that the agglomerates in the nanocomposites with higher content of MWCNT act as large particles and cause to higher apparent filler loading. These agglomerates confine polymer in the void space between MWCNT and effectively reduce the volume fraction of the epoxy polysulfide matrix. .Similar results have been reported in the last literature ${ }^{(15,23-25)}$. An explanation for this behavior may be offered by considering the presence of a weak Van der Waals force between individual graphen shells of the carbon nanotubes, causes easy trip between the shells. Therefore, by higher content of MWCNTs, the nanotubes in the epoxy polysulfide matrices can be drawn layer by layer providing toughness to the sample. Also, pure MWCNT are pulled out more easily when the specimen subjected to tensile or fracture ${ }^{(26)}$. Good dispersion of MWCNT in the polymer matrices reduces the stress centralization and causes uniform stress distribution fracture strain of untreated MWCNTs/epoxy polysulfide nanocomposites reduced by adding MWCNT value which this indicates tendency to brittle epoxy polysulfide nanocomposites These experimental ${ }^{[27]}$ results are in agreement with the available data in a previous work ${ }^{(15)}$.

\section{4-WEAR RATE TEST}

Wear is the progressive loss of substance from the surface of the body brought about by mechanical action. A pin-on-disk test setup was used for slide wear experiments. All experimental data on the slide wear rate of blends and composites is divided into two parts:

First part: gives the results obtained from the polymeric blends before adding the reinforcement. 
Second part: gives the results obtained from the polymeric blends and additives. Wear debris can be measured either as a weight loss or as a change in volume or size of one or both of the rubbing members. Research results indicate the use of both of these measures of wear, and the following three distinct wear criteria have been proposed ${ }^{(28):}$

1. Linear wear rate:-

$\mathrm{k}_{\mathrm{l}}=\frac{\text { thickness of layer removed }}{\text { sliding distance }}=\frac{h}{l}$

2. Volumetric wear rate

$\mathrm{kv}=$ volume of layer $\frac{\text { removed }}{\text { sliding }}$ distance $*$ apparanet area $=\Delta v / l A a$

3. Energetic wear rate:-

$\mathrm{ke}=$ volume of layer removed $/$ work of friction $=\Delta v / F L$

The linear and volumetric wear rates are less dimensions and also identical since $\Delta v=$ Aah. The energetic and linear wear rates are related by:-

$\mathrm{k}_{\mathrm{e}}=\mathrm{k}_{\mathrm{l}}\left(\mathrm{A}_{\mathrm{a}} / \mathrm{F}\right)$

Where $\mathrm{F}$ is the force of friction, $\mathrm{k}_{\mathrm{E}}$ is also referred to as the energy index of abrasion. The mass change of the specimen is measured as the difference in mass of the specimen recorded before and after test, for mass loss measurements, the wear rate is calculated from:-

Wear rate $=\Delta \mathrm{W} / \mathrm{S}_{\mathrm{D}} \quad(\mathrm{gm} / \mathrm{cm})$.

Where $\Delta \mathrm{W}$ is the mass loss $(\mathrm{gm})$ and $\mathrm{S}_{\mathrm{D}}$ is the sliding distance $(\mathrm{cm})$ because wear is a surface effect, surface treatments and coatings play an important role in improving wear resistance. Lubrication can be considered to be a way of keeping surfaces apart and so reducing wear ${ }^{[28]}$. Different kinds of polymer blends have been studied by some researchers, and it is found that the friction and wear behaviors of polymers vary continuously with compositions, the friction coefficient and wear resistance of blends are superior to those of component polymers and reach optimum at certain compositions. The wear process involves a number of complex interactions, but it can be considered to be caused by the energy created by the frictional work and released during sliding within the contact zone. The mode in which the frictional energy is dissipated depend on the contact configuration, which therefore, should be considered as an important factor in friction and wear behavior of polymer. in this research wear rate is calculated for different samples with different percentage of CNT as shown in the Fig.(6) and fig.( 7) as can be observed the wear rate of $0.2 \%$ MWCNTs is higher than that of $.4 \%$ and $0.6 \% \mathrm{MWCNT}$ because CNT reinforcement enhance resistant of material to wear. The wear rate of blend at loads $(5,10,15) \mathrm{N}$ is lower than the epoxy resin, blend $(0.6 \%$ MWCNT) has lower wear rate than other blends. The presence of plasticizer additives increase the free volume and convert it from a rigid to more flexible matrix as can 
be observed from samples surface before test which is smooth and homogenous and after wear where the surface become not homogenous and the wear direction is obvious as in Fig.(8).

\section{CONCLUSION}

In this research. The blend of epoxy polysulfide resin has been reinforced by pure MWCNTs. tensile tests were done on prepared samples to evaluate the effect of presence MWCNTs in epoxy / polysulfide matrices. Results showed tensile strength and Young's module increase by adding MWCNTs, but this improvement decreased when MWCNTs increased in their content. Wear rate showed to be lower for samples with MWCNTs reinforcement than that of epoxy/polysulfide blend. Increasing MWCNTs content cause an increase in wear rate.

\section{REFERENCES}

1. http://www.akzonobel.com/sulfurderivatives/products/thioplast_eps. [09.02.13]. 2013

2. Peterson EA, Rees M, Fiorillo A. Epoxy terminated liquid polysulfide polymer for use in adhesives and coatings. Issue 877 of creative manufacturing engineering program, Society of Manufacturing Engineers; 1986.

3. Sui G, Zhong WH, Yang XP, Yu YH, Zhao SH. Preparation and properties of natural rubber composites reinforced with pretreated carbon nanotubes. Polym Adv Technol 2008; 19:1543-9.

4. Khare R, Bose S. Carbon nanotube based composites - a review. J Miner Mater Charact Eng 2005; 4:31-46.

5. Kun Tao, Yang Sh, Grunlan JC, Kim YS, Dang B, Deng Y, et al. Effects of carbon nanotube fillers on the curing processes of epoxy resin-based composites. J Appl Polym Sci 2006; 102:5248-54.

6. Liu TX, Phang IY, Shen L, Chow SY, Zhang WD. Morphology and mechanical properties of MWCNT reinforced nylon-6 composites. Macromolecules 2006; 37:7214-22.

7. Wang Q, Dai J, Li W, Wei Zh, Jiang J. The effects of CNT alignment on electrical conductivity and mechanical properties of SWNT/epoxy nanocomposites. Compos Sci Technol 2008; 68:1644-8.

8. Jin FL, Ma CJ, Park SJ. Thermal and mechanical interfacial properties of epoxy composites based on functionalized carbon nanotubes. Mater Sci Eng: A2011; $528: 8517-22$. 
9. Yang Y, Gu M, Jin Y. Cure behavior and thermal stability analysis of multiwalled carbon nanotube/epoxy resin nanocomposites. J Appl Polym Sci.2008; 110:2980-8.

10. Guchhait PK, Bhandari S, Singh S, Rahaman M. Study on the effect of nanosilica particles on morphology, thermo-mechanical and electrical properties of liquid polysulfide modified epoxy hybrid nanocomposites. Int J Plast Technol 2011; $15: 150-62$.

11. Guchhait PK, Rahaman M, Nayak L, Chaki TK. Preparation and characterization of polyurethane-polysulfide miscible blend nanocomposites: effect of nanoclays reinforcement on morphology, mechanical and thermal properties. Int Polym Process 2012; 4:461-8.

12. Quinghua Zhang, Li J, Zhao X, Chen D. Preparation and characterization of alkylated carbon nanotube/polyimide nanocomposites. Polym Int 2009; 58:557-63.

13. Shi JH, Yang BX, Goh SH. Covalent functionalization of multiwalled carbon nanotubes with poly (styrene-co-acrylonitrile) by reactive melt blending. Eur Polym $\mathbf{J}$ 2009; 45:1002-8.

14. Barick AK, Tripathy DK. Preparation, characterization and properties of acid functionalized multi-walled carbon nanotube reinforced thermoplastic polyurethane nanocomposites. J Appl Polym Sci 2011; 124:812-23.

15. Montazeri A, Javadpour J, Khavandi AR, Tcharkhtchi A, Mohajeri A. Mechanical properties of multi-walled carbon nanotube/epoxy composites. Mater Des 2010; 31:4202-8.

16. Eklund PC, Holden JM, Jishi RA. Vibrational modes of carbon nanotubes: spectroscopy and theory. Carbon 1995; 33:959-72.

17. Liang EJ, Ding P, Zhang HR, Guo XY, Du ZL. Synthesis and correlation study on the morphology and Raman spectra of $\mathrm{CNx}$ nanotubes by thermal decomposition of ferrocene/ethylenediamine. Diamond Relat Mater 2004; 13:69-73.

18. Luo Y, Zhao Y, Cai J, Duan Y, Du S. Effect of amino-functionalization on the interfacial adhesion of multi-walled carbon nanotubes/epoxy nanocomposites. Mater Des 2012; 33:405-12.

19. Osswald S, Flahaut E, Ye H, Gogotsi Y. Elimination of D-band in Raman spectra of double-wall carbon nanotubes by oxidation. Chem Phys Lett 2005; 402:422-7.

20. Jorio A, Saito R, Hafner JH, Lieber CM, Hunter M, McClure T, et al. Structural (n,m) determination of isolated single-wall carbon nanotubes by resonant Raman scattering. Phys Rev Lett 2001; 86:1118-21. 
21. Liao YH, Marietta Tondim O, Liang Z, Zhang C, Wang B. Investigation of the dispersion process of SWNTs/SC-15 epoxy resin nanocomposites. Mater Sci Eng A $2004 ; 385: 175-81$.

22. Santos AS, Leite TON, Furtado CA, Welter C, Pardini LC, Silva GG. Morphology, thermal expansion and electrical conductivity of multiwalled carbon nanotube/epoxy composites. J Appl Polym Sci 2008; 108:979-86.

23. Bai JB, Allaoui A. Effect of the length and the aggregate size of MWNT on the improvement efficiency of the mechanical and electrical properties of composite materials.

24. Zhou Y, Pervin F, Rangari VK, Jeelani S. Fabrication and evaluation of CNF filled carbon/epoxy composite. Mater Sci Eng 2006; 426:221-8.

25. Seok Song Y, Ryoun Youn J. Influence of dispersion states of CNT physical properties of epoxy nanocomposites. Carbon 2005; 43:1378-85.

26. Kim JA, Seong DG,Kang TJYoun JR.Effect of surface modification on mechanicalpropertiesofCNT/epoxycomposites.Carbon2006;44.1898-905.

27. Ayatollahi MR, Shadlou S, Shokrieh MM. Fracture toughness of epoxy/multiwalled CNT-composites under bending and shear loading conditions. Mater Des 2011; 32: 2115-24.

28. Moore, D. F., "The Friction and Lubrication of Elastomers", Vol. 9, Pergamon Press Ltd., Germany, 1972. .

Table (1): epoxy mechanical properties ${ }^{[1]}$.

\begin{tabular}{|c|c|}
\hline Test method & Typical results \\
\hline Compressive strength & $70.0 \mathrm{MPa}$ at $20{ }^{\circ} \mathrm{C}$ \\
\hline Tensile strength & $26.0 \mathrm{MPa}$ at $35^{\circ} \mathrm{C}$ \\
\hline Flexural strength & $63.0 \mathrm{MPaat} 35^{\circ} \mathrm{C}$ \\
\hline Young modulus in compression & $16 \mathrm{GPa}$ \\
\hline Pot life & 90 minutes at $20{ }^{\circ} \mathrm{C}$ \\
& 40 minutes at $35^{\circ} \mathrm{C}$ \\
\hline Specific gravity & 1.04 \\
\hline Mixed viscosity & 1.0 poise at $35^{\circ} \mathrm{C}$ \\
\hline
\end{tabular}


Tabel.(2): properties of polysulfide ${ }^{[1]}$.

\begin{tabular}{ll}
\hline Property & Typical value or description \\
\hline General chemical structure & $\sim[\mathrm{R}-\mathrm{S}]_{x}$ m \\
& $\mathrm{R}=\left(\mathrm{CH}_{2} \mathrm{Cl}\right)_{2}$ or $\left(\mathrm{CH}_{2}\left(\mathrm{OCH}_{2} \mathrm{CH}_{2} \mathrm{Cl}\right)_{2}\right.$ \\
Service temperature $\left({ }^{\circ} \mathrm{C}\right)$ & -50 to 95 \\
Cold resistance & Fair \\
Ageing resistance & Excellent \\
Sunlight resistance & Medium \\
Ozone resistance & Excellent \\
Heat resistance & Poor \\
Flame resistance & Poor \\
Fluid resistance: & \\
Aliphatic & Excellent \\
Aromatic & Excellent \\
Mineral resistance & Excellent \\
Animal or vegetable resistance & Excellent \\
Water resistance & Good to excellent \\
Electrical resistance & Moderate \\
Optimum properties & Maximum oil or solvent resistance \\
\hline
\end{tabular}

a Depends upon the percentage of polymer and curing agent used.

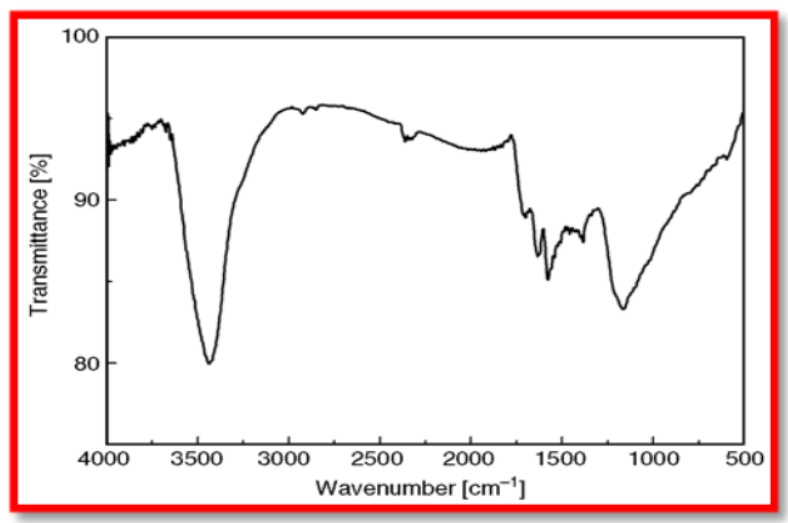

Fig. (1): FTIR of pristine CNT. 


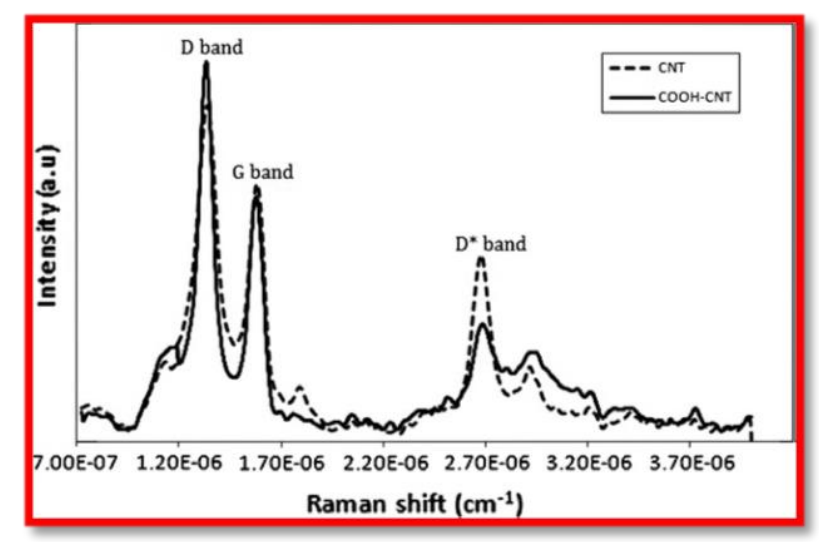

Fig. (2): Raman spectrum of CNT.
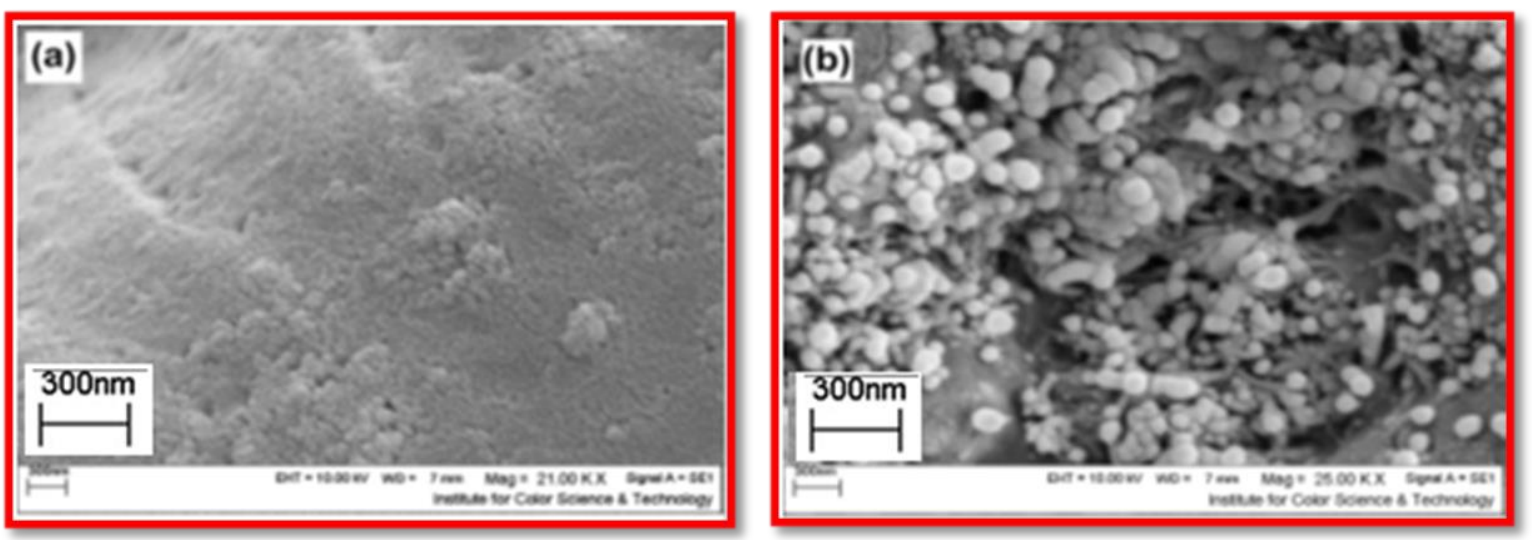

Fig. (3): SEM images from fracture surfaces of (a) the neat epoxy polysulfide resin and (b) the $0.2 \mathrm{wt} \%$ MWNT/epoxy polysulfide nanocomposite.

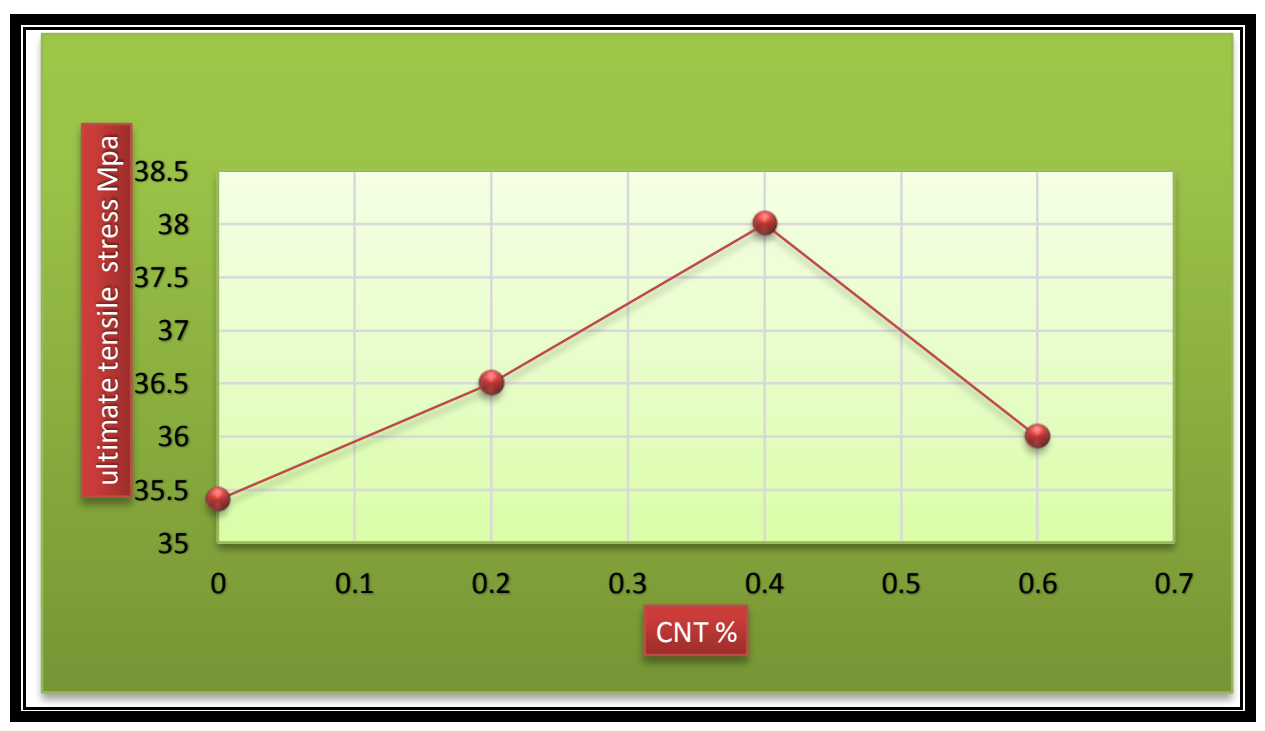

Fig. (4): carbon nano tube effect on stress of $2 \%$ polysulfide/epoxy blend. 


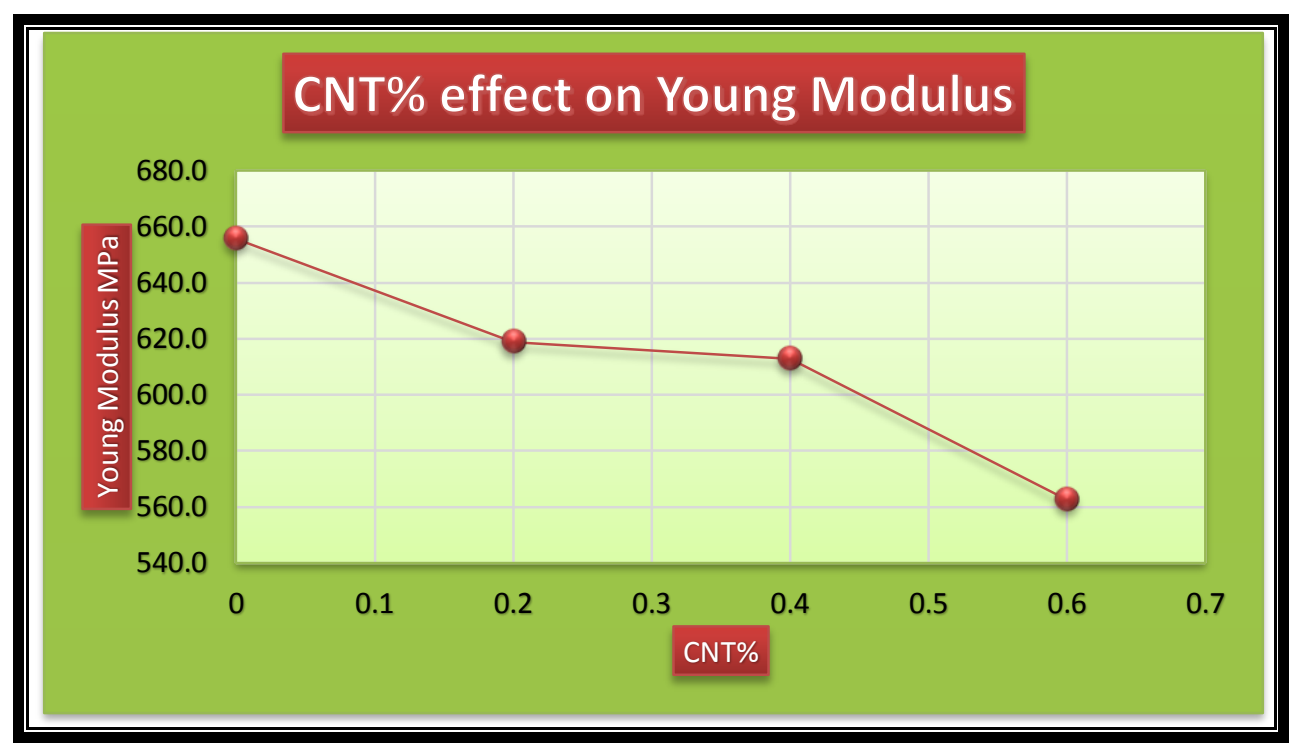

Fig. (5): CNT effect on young modulus.

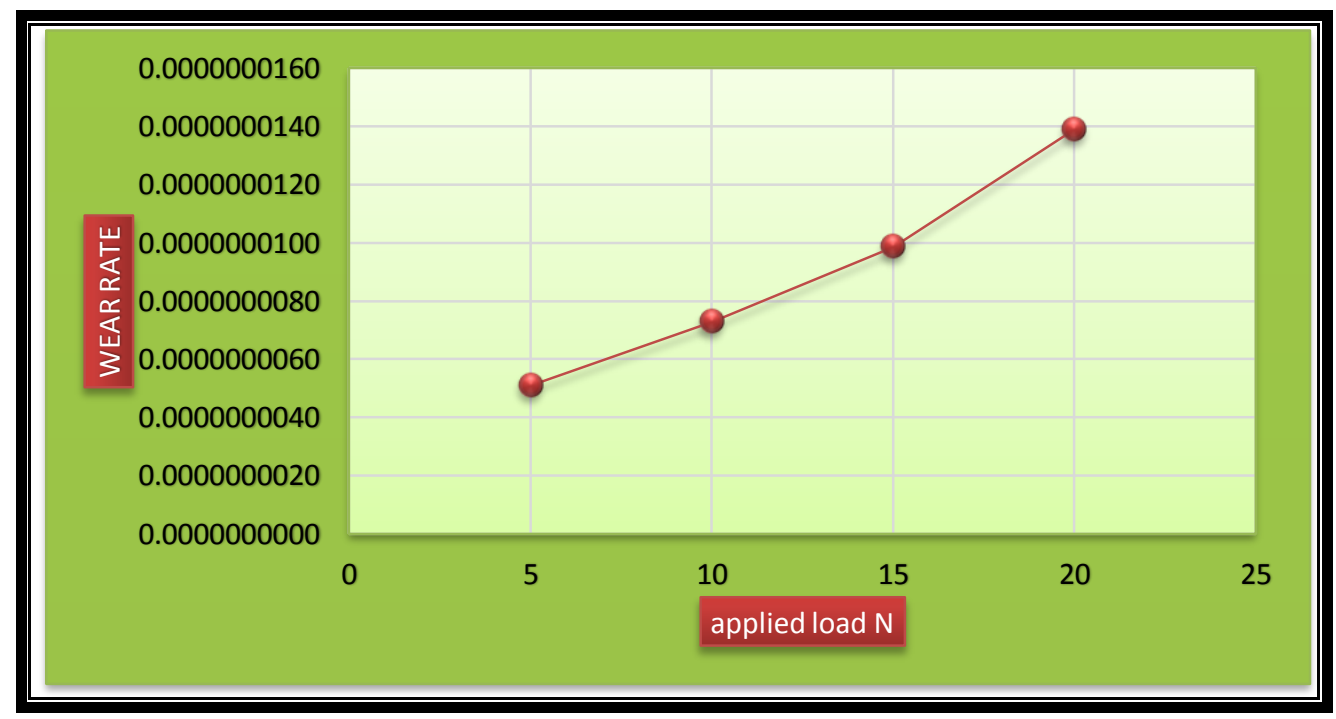

Fig. (6): effect of load on wear rate of epoxy/polysulfide blend. 


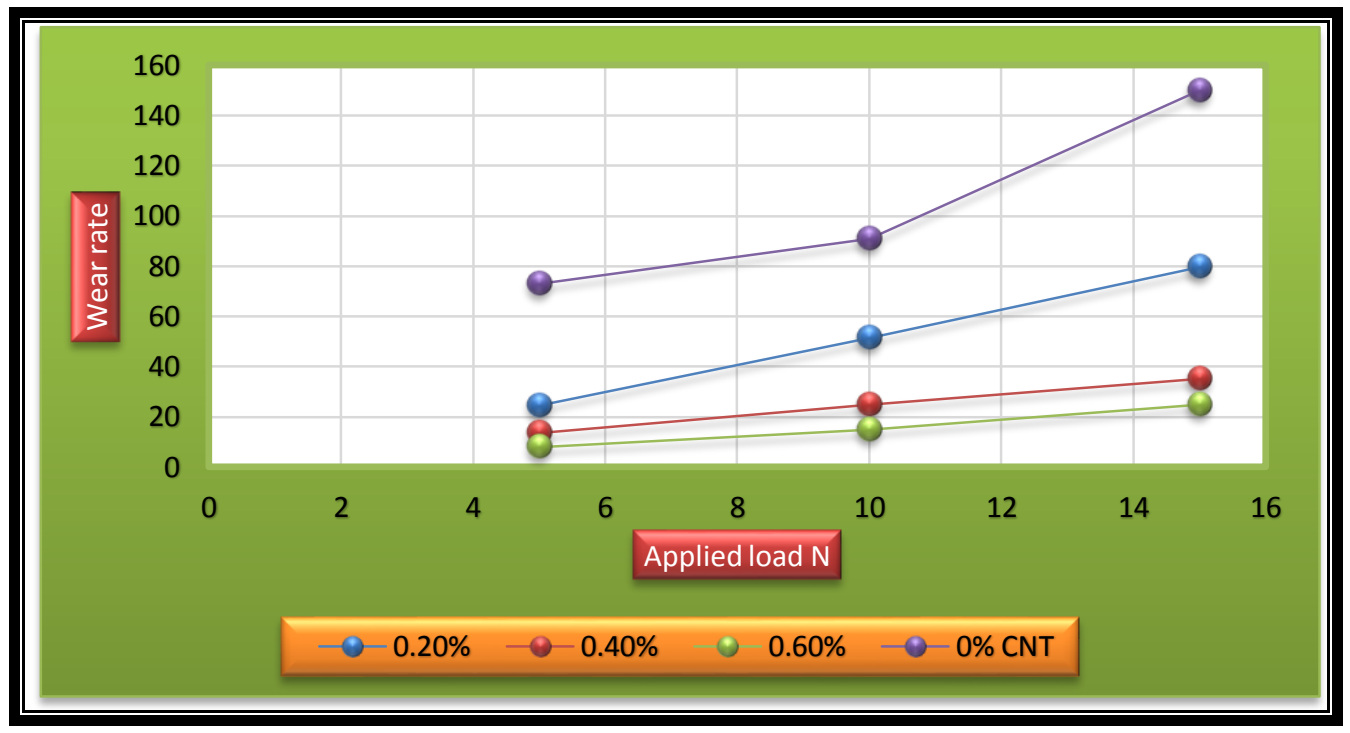

Fig. (7): effect of load on wear rate of carbon nano tube reinforced composite materials.

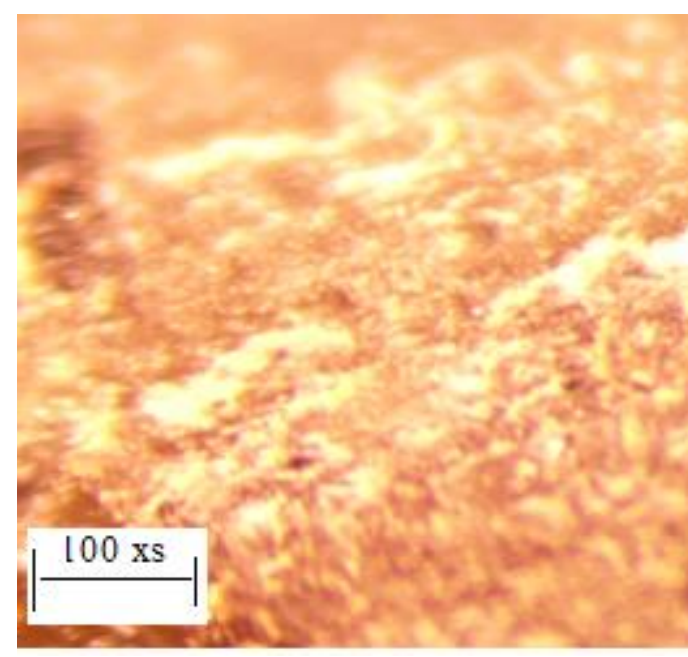

(a)

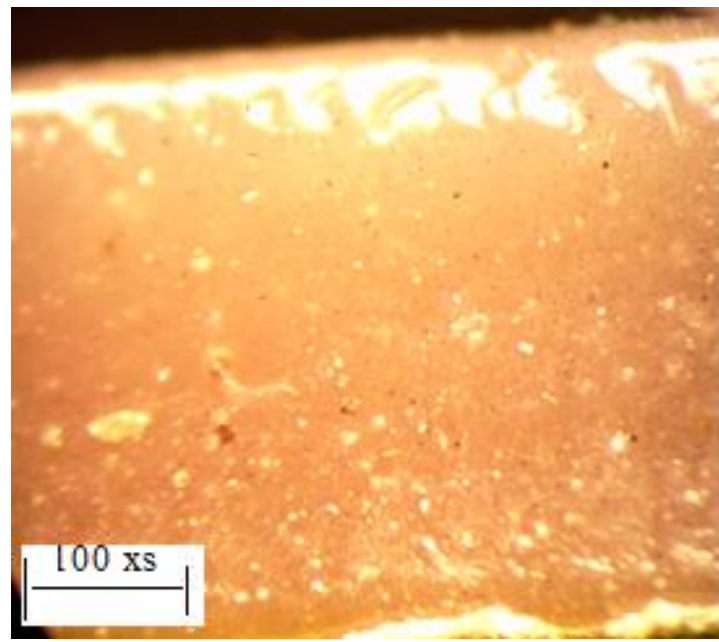

(b)

Fig. (8): stereo optical microscope samples surface after wear (a) and before wear (b) of epoxy/polysulfide/CNTs. 


\title{
بعض الخصائص الميكانيكية لمتراكبة خليط الايبوكسى-بولى سلفايد المدعم بانابيب كربونية نانوية خلية
}

\author{
عدنان نعمة عبود 1، ابتهال عبد الرزاق 2، اخلاص عيدان قادر3 3

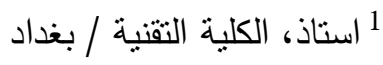

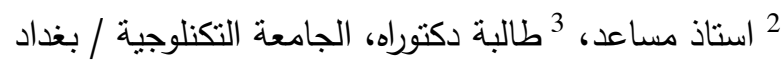

فىى البحث نم استخدام انابيب الكربون النانوية لتقويةخليط الاييوكسى مع البولو سلفايد وقيمت خواص الثد

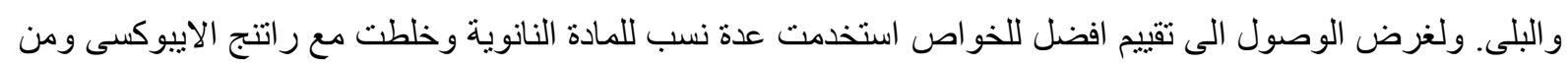

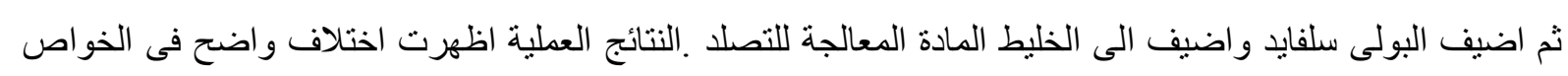

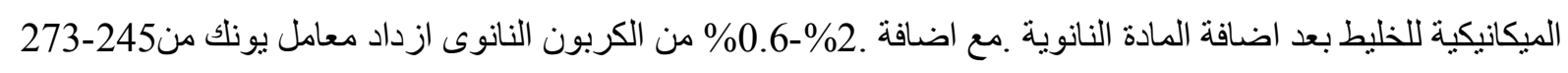

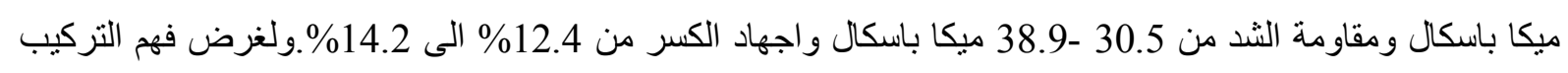

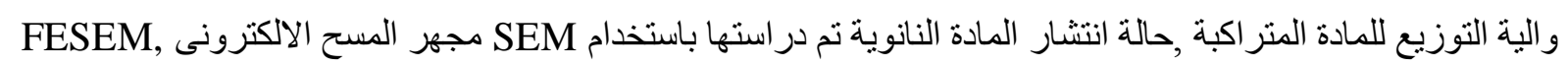
(مجهر المسح الالكترونى للعناصر المحددة). 